\title{
ADMINISTRACIÓN Y CONTRATISTAS DE OBRAS PÚBLICAS EN LA ESPAÑA ILUSTRADA
}

\author{
(ADMINISTRATION \& CONTRACTORS OF PUBLIC WORKS IN THE ENLIGHTENED SPAIN)
}

\author{
José María Menéndez, \\ Doctor Ingeniero de Caminos \\ Profesor Titular de la Cátedra de Transporte \\ E.T.S. de Ingenieros de Caminos. Madrid-España.
}

\section{RESUMEN}

Durante el reinado de Carlos III se inició la construcción de la red de caminos radiales. En el presente artículo se repasan los procedimientos administrativos relativos a la ejecución de los proyectos de ingeniería en dicha época. Se analizan las formas de contratación, los pliegos de condiciones, los tipos de materiales utilizados, el "remate" o adjudicación de la obra, y las condiciones financieras de estas adjudicaciones.

Todo ello permite considerar los antecedentes de muchos de los procedimientos todavía actuales.

\section{SUMMARY}

During the reign of Charles III the construction of radial road-network was set up. This current article tries to review the administrative process referring to the execution of the engineering projects in those days. It analyses the means of contract conditions required, the type of material used, the "remate" or the assignment of works and the financial conditions of these assignments.

All this leads to the consideration of the past data in many of the processes which are still in use today.

\section{INTRODUCCIÓN}

Poco tiempo después de la subida al trono de Carlos III, la Corona encargó la construcción de una red de caminos radiales de "moderno" trazado y acorde con las necesidades del sistema de Estado. De esta etapa datan dos documentos legislativos cruciales para la historia de las Obras Públicas en España; nos referimos al "Real Decreto para hacer Caminos rectos y sólidos en España que faciliten el comercio de unas provincias a otras..." y el "Real Reglamento que S.M. quiere se observe en las obras de Caminos, que se dignó mandar executar...", fechados ambos en 1761 y que sientan las bases de lo que la historiografía contemporánea acostumbra a llamar Plan Ward y que más correcto sería lla- mar Plan Esquilache, pues a este ministro y no a otro funcionario de la Administración se debe el primer esfuerzo para la puesta en marcha del ambicioso proyecto.

Empleando la documentación procedente de este período histórico, consultada fundamentalmente en el Archivo General de Simancas, ha sido elaborado el presente artículo, con la intención de constituir una primera aproximación al estudio del entramado administrativo que acompañó a la ejecución de los proyectos de ingeniería civil en el reinado de los primeros Borbones, cuestión ésta tan poco tratada hasta la fecha por los estudiosos de la Historia. 
突

COPIA DEL REAL DECRETO expedido para bacer Caminos rectos ,y sóli. dos en Españia, que faciliten el Comercio de unas Provincias á otras, dando principio por los de Andalucia, Catbaluria, Galicia, y' Palencia.

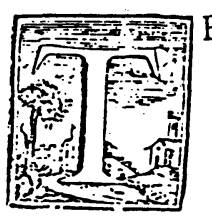

Engo confiderado, que uno de los cftorvos capitales de in felicidad pùblica de cftos mis Rcynos es:el mal cftado cn que fe hallan fus $\mathrm{C}_{\mathbf{a}}$ : minos por la fuma dificultad, $y$ aun impolsibilidad de ufarlos en todos los tiempos del ańo, para conducir con $\mathrm{fa}_{2}$, cilidad los Frutos, y Generos, que fobran en unas Provincias, á orras, que eftàn necefsitadas de ellos, introducir en las interiores los Generos eftrange. ros, que influyen a la abundancia, que conviene á los Pucblos , y llcvar à los Puertos para extraer á otros Paífes los que no fon precifos en eftos, quedando privadas las Provincias efteriles del focorro de las fértiles, $y$ de los auxilios, que mutuamente pucden comunicarfe todas para la mayor comodidad de fus habitantes, pucs fobre pagar unos crecidos portes los intereflidos en las cargas, experimentan los conductores muchas farigas, que perjudican, y cmóarazan notablemente la frequencia, y mulriplicacion de los tranfportes, gue fon tan utiles al Eftado: y reflexionando tambien, quue los bucnos Caminos, con algunos Canales para ricgo,

Real Decreto de Carlos III de 1761.

Real Reglamento de Carlos III de 1761.

\section{LA CONTRATACIÓN}

En terminología de la época, el método propugnado por el Reglamento de 1761 para la contratación de obras civiles por parte del Estado, se denominaba "administración a jornal", modalidad de actuación que consistía en que la mano de obra era contratada por un tiempo indefinido (usualmente los seis meses, que en cada año eran dedicados, según indicaba el Reglamento, a la ejecución de las obras), y actuaba a las órdenes de un equipo técnico y administrativo fijo (Ingenieros, Comisario de Guerra, Contadores, etc.) que desarrollaban un plan de acción previsto por el Ingeniero Director bajo la tutela del Subdelegado.

Existía otra fórmula alternativa, similar a ésta, la "administración a destajo" en la que al personal no cualificado se le pagaba por obra realizada (vara cúbica a desmontar, carro de cal aprontado en obra, etc.).
COPIA DEL REAL REGLAMENTO, ì Inftruccion, que $S$. $M$. quiere Je obferve en la Obra de Caminos, que fe dignò mandar executar por Real Decreto de diez de Funio de efte año.
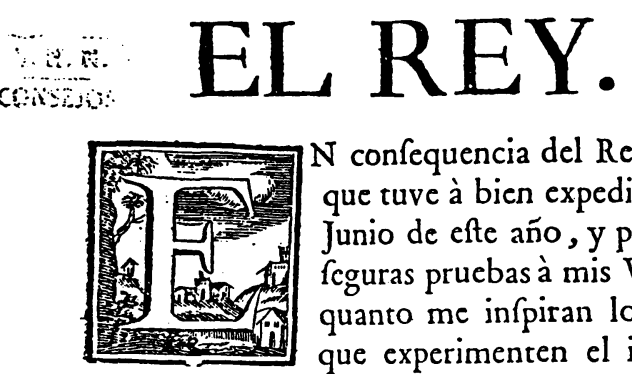

N confequencia del Real Decreto, que tuve à bien expedir en diez de Junio de efte año, y para dár mas fcguras pruebas à mis Vaffallos, de quanto me infpiran los defeos de que experimenten el importante, y util beneficio, que ha de redundarles de la execucion de Caminos públicos, que faciliten la mayor comodidad para fu trato, y comercio, he mandado formar por mi Secrerario de Eftado, y del Defpacho de Hacienda, Marqués de Squilace, la prefente Inftruccion, mediante la qual fe configa en todas las Provincias la uniformidad que fe requiere en la dirección de efta importancia, pudiendo dicho mi Secretario, como. Superintendente General de Caminos, fubdelegar efte encargo en las perfonas que cligiere, con todas aquellas facultades que confpiren al mayor progreffo, y acierto, baxo las reglas contenidas en los articulos figuientes:

\section{I.}

Los Capitanes Generales, Comandantes Generales, è Intendentes de Exercito, y Provincia ; los Governadores de las Plazas, y Caftillos, Corregidores, Alcaldes, y demàs Jufticias de las Ciudades, Villas,

A y

A estos dos procedimientos (cada uno de ellos con sus detractores y seguidores conforme a los mismos argumentos que se acostumbran a emplear en nuestros días respecto de las fórmulas "jornal" y "destajos") se oponía el procedimiento del "asiento" consiśtente en delegar en un individuo o compañia la ejecución de toda o parte de la obra, reservándose el Estado el papel de director ( $y$ en ocasiones también de inspector) con lo que obviamente resultaba inútil todo el entramado organizativo que se elaboró al comienzo del Plan Esquilache, y que se plasmaba en el reglamento de 4 de diciembre de 1761.

El asentista establecía una relación contractual con la Administración fijada por la normativa legal y que se plasmaba en cierto tipo de documento que evolucionó relativamente poco a lo largo del siglo XVIII. Aunque a las peculiaridades de estos "contratos" vamos a tener ocasión de referirnos con detalle más adelan- 
te, anticiparemos dos sobresalientes omisiones que son características en todos los que hemos podido consultar. La primera es que el contrato no establece nunca el coste total del proyecto cuya ejecución se pacta, sino sólo los precios unitarios. La segunda, que tampoco se establece en ningún caso el plazo de ejecución (cuando excepcionalmente se menciona esta cuestión se hace en términos imprecisos, tales como el "asentista se ha de obligar a executar la obra con la mayor vigilancia, viveza o prontitud" o expresiones similares).

En términos absolutos fue el "asiento", con toda seguridad, la fórmula empleada con más asiduidad en la ejecución de las obras de caminos, antes y después del decreto de 1761. En cualquier caso esta actitud dubitativa a la que antes nos referíamos, produjo resultados, que en ciertos casos concretos pueden calificarse como de realmente curiosos. Así por ejemplo, en la carretera de Asturias (etapa 1771-78) el reparto de los fondos anuales entre obras realizadas por asiento y obras realizadas por administración, presenta unas alternancias anuales que superan en varias ocasiones la relación de 1 a 10. Dos décadas antes, el otro gran paso de la Cordillera Cantábrica, el camino de Reynosa a Santander fue realizado por asiento que se "remató" (1), precisamente por Marcos de Vierna, quien años después sería funcionario del Consejo de Castilla y su asesor en materia de Obras Públicas. Entre una y otra fe- cha el camino general de Galicia fue ejecutado hasta 1763 , mediante administración a jornal estableciéndose a finales de ese año un "asiento general" pactado con el empresario José Iglesias (2) mediante documento que hubo de ser rescindido apenas unos meses después, a principios del 64 "por haberse perdido el asentista" (entiéndase arruinado) y tras ello se volvió de nuevo a la administración, sistema que se mantuvo hasta que en abril de 1764, Le Maur se hizo cargo de la dirección de las obras disponiendo el procedimiento de los "pequeños destajos" que se siguieron aún después de su destitución y a pesar de que su sustituto Baltasar Ricaud era partidario de volver al "asiento".

Cuando la Administración hace el papel de patrono, es decir, cuando opta por la fórmula de ejecutar la obra por "administración", el equipo de "funcionarios" a las órdenes del Subdelegado se encarga de abonar los salarios a los jornaleros, de la compra de herramientas que almacena en rudimentarios "parques", dotados en ocasiones de fragua en la que se recompone el utillaje deteriorado, así como del aprovisionamiento de materiales (arena, cal, piedra), usualmente confiscando carros entre los pueblos de la comarca mediante el socorrido "repartimiento" del que recogemos un ejemplo en el cuadro I que puede dar una idea de la envergadura de estas operaciones de confiscación, derivadas con seguridad de la absoluta penuria de medios de transporte que se padecía en la época.

Cuadro I. Ap.

\begin{tabular}{|c|c|c|c|c|c|}
\hline $\begin{array}{l}\text { Repartimiento entre los } \\
\text { se necesitan para el tr } \\
\text { el Corrál. (1). }\end{array}$ & $\begin{array}{l}\text { gare } \\
\text { ajo d }\end{array}$ & $\begin{array}{l}\text { ue avajo se expresan } \\
\text { Camino transversal, }\end{array}$ & trein & $\begin{array}{l}\text { cinco Carros que diari } \\
\text { á ejecutando entre Alta }\end{array}$ & $\begin{array}{l}\text { amente } \\
\text { mira, y }\end{array}$ \\
\hline Provincia de Santiag & & Provincia de Betan & 205 & Provincia de La Co & ruña \\
\hline & arros & & Carros & & Carros \\
\hline Jur. $^{\text {on }}$ del Valle de Barcia: & & Jur. ${ }^{\text {on }}$ Al. de Betanzos: & & Vara de Crendes: & \\
\hline $\begin{array}{l}\text { S. Estevan de Paleo } \\
\text { S. Pedro de Quembre } \\
\text { Sta. Christina de Montoto } \\
\text { Sta. Mariña de Veyrn } \\
\text { Santiago de Sumio }\end{array}$ & $\begin{array}{l}1 \\
1 \\
1 \\
1 \\
1\end{array}$ & $\begin{array}{l}\text { S. Martín de Fabenyo } \\
\text { S. Vicente de Vigo } \\
\text { Sta. Eulalia de Cañas } \\
\text { Sta. M. } \text {. de Sarnudones } \text { S. Miguel de Figueroa } \\
\text { S. Julián de Cabrana } \\
\text { S. Salvador de Brienes } \\
\text { S. Pedro de Visoño }\end{array}$ & $\begin{array}{l}1 \\
1 \\
1 \\
2 \\
2 \\
1 \\
1 \\
1 \\
\end{array}$ & $\begin{array}{l}\text { S. Payo de Brejo } \\
\text { S. Juan de Anceis } \\
\text { Sta. M. }{ }^{\mathrm{a}} \text { de Vigo }\end{array}$ & $\begin{array}{l}1 \\
2 \\
1\end{array}$ \\
\hline & 5 & & 10 & & 3 \\
\hline & & Coto de Avegondo: & & Vara del Valle de Veiga: & \\
\hline & & $\begin{array}{l}\text { Sta. Eulalia de Avegondo } \\
\text { S. Ciprian de Drives }\end{array}$ & $\begin{array}{l}1 \\
1\end{array}$ & $\begin{array}{l}\text { S. Esteban de Sueyro } \\
\text { Santiago de Castelo } \\
\text { Sta. M. }{ }^{\text { de Zelas }} \\
\text { S. Silvestre de Veiga } \\
\text { S. Pedro de Lodoño } \\
\text { S. Estevan de Culleredo } \\
\text { S. Salvador de Orro }\end{array}$ & $\begin{array}{l}1 \\
2 \\
1 \\
2 \\
1 \\
1 \\
1\end{array}$ \\
\hline & & & 2 & & 9 \\
\hline & & Coto de Oza: & & Jur. $^{\text {on }}$ de Encrobas: & \\
\hline & & S. Tirso de Mavegondo & 1 & $\begin{array}{l}\text { S. Román de Encrobas } \\
\text { S. Andres de Meyrama }\end{array}$ & $\begin{array}{l}2 \\
1 \\
\end{array}$ \\
\hline & & & 1 & & 3 \\
\hline
\end{tabular}


Por el contrario cuando la obra se realiza por "asiento", el Estado adopta un papel espectante. Su misión inspectora da derecho a los ingenieros nombrados por el subdelegado a obligar al asentista a rectificar o demoler las unidades de obra incorrectamente realizadas. Periódicamente, y mediando el acuerdo entre las partes, el facultativo certifica las unidades ejecutadas y con el visto bueno del Comisario, el asentista cobra su trabajo.

El procedimiento usual, casi único, mediante el que un asentista quedaba encargado de la ejecución de una obra de caminos era la subasta pública. Los participantes en esta subasta suelen ser empresarios individuales, vecinos normalmente de los pueblos próximos (aunque un reducido grupo de apellidos: Martinengo, Bernasconi y, sobre todo, Vierna, desarrollan su actividad en todo el territorio nacional). En ocasiones un grupo, normalmente reducido, de individuos se asocian en la puja, por lo que no es estraño que en la actas notariales de las subastas se haga referencia a razones sociales con la misma fórmula: fulano de tal y Cía. que se emplea en nuestros días.

\section{PLIEGOS DE CONDICIONES}

Los documentos que sirven de referencia para participar en la puja son elaborados, usualmente, por un ingeniero o facultativo al servicio de la Administración. Se les denomina ya por aquel entonces "Pliegos de Condiciones" y aunque no están sometidos a una fórmula oficial (3), es usual que todos posean una estructura similar: en esencia constituyen breves tratados del buen hacer en materia de construcción de caminos y puentes, que se acompañan de algunos otros artículos relativos a ciertas obligaciones burocráticas del asentista.

La única referencia que detalla la obra a ejecutar suele ser el título del documento, que a veces se despacha con relativa brevedad, por ejemplo: "Condiciones a que se deber arreglar la persona, o personas que tomaren el asiento, de las Obras y relleno del nuevo $\mathrm{Ca}$ mino Real desde Ocaña a Villatobas" (4), pero en ocasiones la necesidad de precisar ciertos puntos que se consideran de interés convierten a los títulos de estos "Pliegos" en pequeñas novelas como sucede con las "Condiciones formadas por el Brigadier Dn. Franco Sabatini... a las que se devieran arreglar el Asentista 0 Asentistas que quisieren hacer postura, a las Escavacaciones, Rehinchidos, Zampeados, Mampostería, Cantería de Piedra Berrogueña [...] y todo los demás que se ofrezca y sean preciso para continuar el nuevo camino que se ha construido por el otro lado del río Manzanares desde la Puerta de Segovia, hasta la Puerta de Castilla y se ha de seguir desde ella hasta encontrarse con el camino del Escorial más allá de Aravaca en que se han de hacer dos puentes uno en el Arroyo de Andriquina y otro en el de Aravaca..."
Con una orientación tan somera sobre la obra a realizar, y ante la ausencia casi general de un proyecto formal de ejecución no debe extrañarnos, como ya hemos comentado, que las referencias a plazos de ejecución y a propuestas globales quedaran excluidos de estos documentos.

Anticipamos que la puja se realizaba (no podía ser de otra forma) sobre el precio de las unidades de obra, único dato económico que tras la subasta pasaba a tener carácter contractual. Este hecho convierte a la contratación "por asiento" que estamos describiendo en una fórmula relativamente próxima a lo que la actual ley de contratos del Estado califica como contratación por administración, empleando el término que en el siglo XVIII indicaba precisamente la figura contraria del "asiento" (5).

Los primeros artículos de los pliegos estaban dedicados generalmente a una descripción tanto de los pertrechos como del personal con que el asentista que quedara encargado de la obra tenía que concurrir a ella: "deber proveerse - dice uno de los pliegos consultados-de buenos operarios, maestros, peones y jornaleros en número necesario y a satisfacción del ingeniero, a quien será facultativo despedirlos si lo hallase conveniente y particularmente a los que no fueren abiles en su oficio, los motins., desvergonzados y todos los que perturban el buen orden y heconomia de la obra..." Y respecto de los útiles corresponderá al asentista proveerse a su costa de "Herramientas mayores y menores", "caballerias", "Máquinas de todas clases" (6), "Andamios", "Cimbras" (7), "Acodalados", "Plantillas", "Escuadras", "Niveles" y "cuantos instrumentos sean necesarios pa. hacer las monteas y demas hasta la conclusión de las obras con los sujetos, útiles e inteligentes para ello..."

\section{MATERIALES Y SUS CALIDADES}

El resto del articulado se centraba en fijar con detalle lo que más arriba hemos denominado las normas del buen hacer (8), al uso en la 2. ${ }^{\mathrm{a}}$ mitad del siglo XVIII, tanto en la elección de los materiales como en su manipulación, la ejecución de mezclas, el empleo de elementos auxiliares, etcétera.

Por lo que se refiere al 1.er punto, la elección de materiales aparte de las consideraciones de carácter general, "Todos sean de los mejores del país", "se elegirán de la mejor calidad", etc., es corriente que a cada uno de ellos se dedique un apartado específico, lo que, a nuestra vez, nos permite realizar una descripción relativamente detallada sobre las calidades y características que de ellos se exigían. Para cada uno de ellos recogemos las que en el conjunto de los documentos consultados nos ha parecido de mayor interés: 
Mamposteria (para obras de fábrica en las que preocupa menos la vistosidad). Se suelen distinguir en los pliegos entre la mampostería en "seco" y la "ordinaria" (algunos llaman a esta última "obra de cal y canto"). En ambos casos la obra deberá estar "bien ligada y ripiada", "buscando a las piedras el mejor asiento y cara y llevando iguales las hiladas" y utilizando piedra que no sea "rubia" ni "granigorda" "ni esté sin cuajar". La mampostería ordinaria se hará "en baño de mortero".

Piedra de sillería (para muros de sostenimiento, "guardaruedas", señales itinerarias, puentes, etc.) "ha de ser de las canteras altas... granimenuda... sin pelos, oyos, vaganteces, ni blandones", "sin endiduras", "y la han de traer de los largos altos y atizonado que se les mande... labrandola y sentandola perfectamente...".

Cal "se ha de apagar bien al uso del país, quince días antes de emplearla, y para que no quede alguna porción viva u escaldada se removerá y batirá bien con el rodillo o battidera como se practica en todas las obras", o también "se ha de hacer la cal en Balsas colada a la Italiana" (9).

Arena "debera ser de la mejor bien granada y limpia de tierra", "de forma que apretandola con la mano esta quede limpia".

Mezclas "si la cal fuera demasiada fuerte se ará con dos capazos de cal y tres de arena, y si fuese regular con uno de cal y dos de arena y esta mezcla bien batida en la Batidera de manera que el mortero resulte perfecto y en la debida forma..." "pasando asín la arena como la cal por criba espesa para que se pueda trabajar con limpieza y agueso", ..."para las cepas de Puentes, y Bovedas, Arcos de favrica se han de hechar tres espuertas de Arena y dos de cal, y para los Mamposteados de otras paredes han de hacer la mezcla regular de dos, y una". En ocasiones la cal, la arena y la elaboración de las mezclas queda a cargo de la Administración exonerando al asentista de todo lo relacionado con ello. Cuando así sucede se hace constar en el "Pliego" una nota al margen. Así, por ejemplo, en las "Condiciones... para el asiento del camino de Galicia..." (10), se indica "La cal, la arena, y el terciarla [se hará] de cuenta del Arbitrio en atención a que sí se adultera este genero, la obra es de ninguna subsistencia, y nunca alcanzan las precauciones para evitar este fraude".

Ladrillos. En casi todos los "Pliegos" se le llama "obra cocida" y en aquellos que están fechados en las provincias de Madrid y Toledo, es muy corriente que se exija que el ladrillo proceda precisamente de la "rivera del Jarama". Respecto de sus características se impone que esté "cocido perfectamente y de modo que esté arrecochado..." "y se ha de mojar hasta que quede emborrachado en Agua y trabajar con la mayor perfección a nivel, plomo y centricalmente...". O Consejo Superio de Investigaciones Científicas Licencia Creative Commons 3.0 España (by-nc)
Afirmado. No es frecuente que este apartado merezca una atención muy detallada en los distintos "Pliegos" consultados y hay cierta tendencia a suponer que el propio paso de los vehículos será quien, con su acción, mejorará las condiciones del firme, siempre que la "capa" esté bien construida "con cama de tierra y arena" y protegidos sus laterales mediante un "encintado" de adecuadas dimensiones, buscándoles a las piedras que formarán el lecho "el mejor asiento y cara" y "llenando los intersticios de guijo y arena con la capa superior de lo mismo, el todo bien ordenado y batido a golpe de pisón". En ocasiones, sin embargo, se llega a un considerable detalle tanto en lo relativo a los tamaños de la piedra a utilizar como a los pasos en que realizará el proceso: así sucede por ejemplo en las "Condiciones formadas para la recomposición del Camino de Valencia desde la salida del RI. sitio de Aranjuez hasta el otro lado del Corral de Almaquer" (11), "Pliego" en el que, sin duda por tratarse de una recomposición, el tema a que nos referimos se describe con todo detaIle. "Es condición - dice el "Pliego"- que se echen generalmente las quatro tongas, la de piedras como puños solo de su altura, otra de piedra de tamaño de huevos de medio pie de altura en el medio, un quarto de pie en los extremos y otra de Almendrilla de una cuarta de altura en medio y a morir con disimulo en las dos cintas de adoquines de los extremos y luego dos pulgadas de Arena en general todo muy apisonado y pasado con rodillos grandes de piedra tirados por Bueyes, o Mulas...". Al referirse a la gradación de los tamaños de la piedra para emplear en afirmados se propone, en ocasiones, utilizar en la capa inferior otros de tamaño algo mayor a los que se indican en el párrafo anterior, se habla entonces de "piedras de cabeza de perro" o de "algo mas que de perro", en cualquier caso se recomienda que las más menudas..."han de ser pasadas por la zaranda y quedar limpias de tierra y arena". Otra práctica no extraña es la de no incluir en el contrato la construcción de la capa más superficial del firme (a la que se suele hacer referencía con el nombre de bombado, o bombao). Así, por ejemplo, en el $\mathrm{Ca}$ mino de Villafranca a Ruitelan (12), justificando la medida "porque esta obra no conviene se haga hasta que las tierras esten del todo asentadas a fin de dexarlo solidamente terminado, y por consiguiente no se contratar por aora de ello".

Hinca de pilotes. Cuando el "Pliego" hace referencia a la construcción de un puente dentro de un tramo de carretera o, como a veces sucede, es especificamente un puente la obra que sale a concurso, usualmente se dedica un apartado a las condiciones en que se ha de realizar la hinca de pilotes y ciertas peculiaridades de éstos (apenas hemos encontrado otras referencias sobre procedimientos de cimentación de pilas de puentes que el pilotaje). Respecto de las características de la madera a utilizar parece haber acuerdo común en que no hay inconveniente de que sea "bravia y resinosa... por ser mas a propossito para el agua"' Su corta deberá 


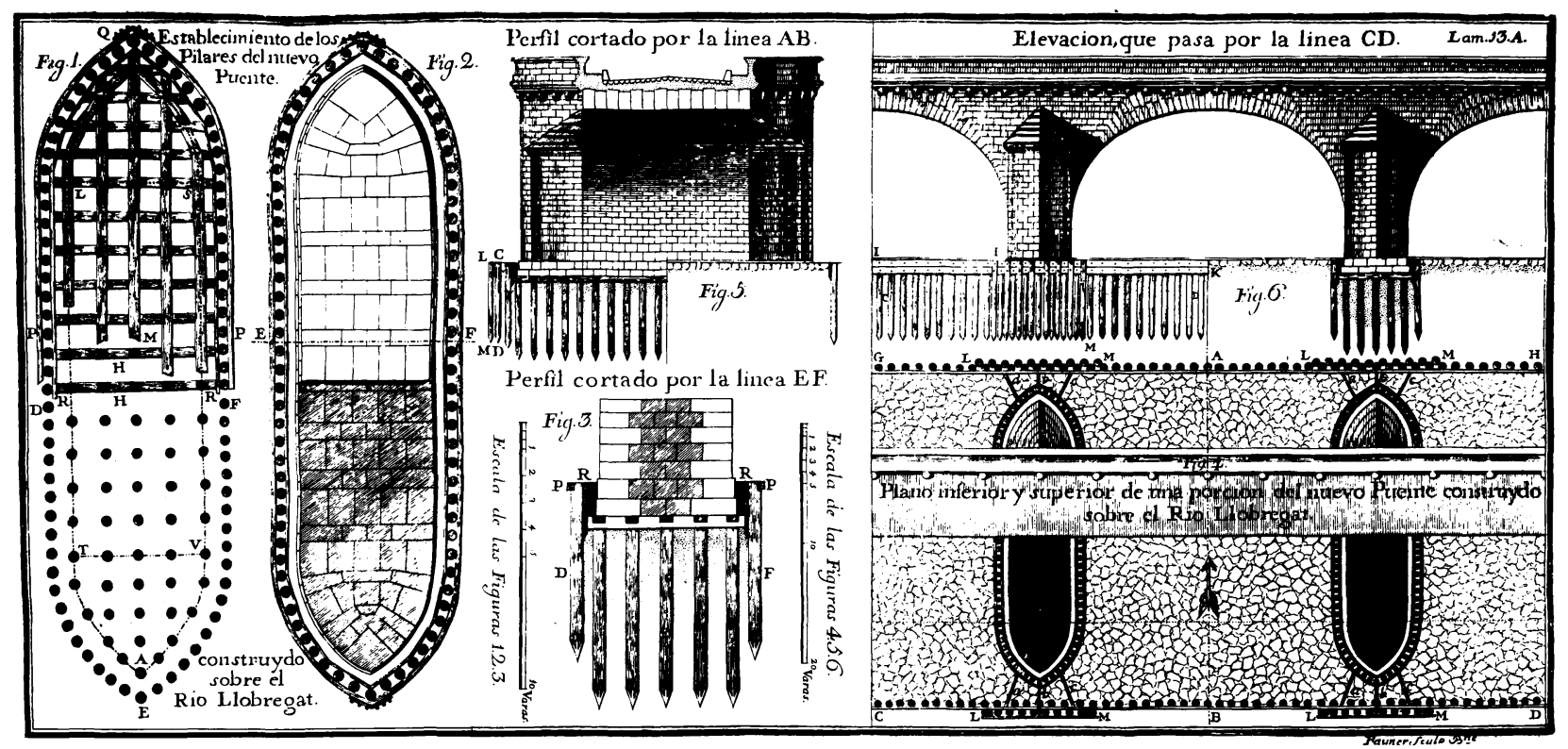

Descripción gráfica del procedimiento de cimentación mediante pilotes, tomada del "Tratado de Fortificación", versión española de la obra de Muller, editada en Barcelona en 1769 y que compendia las técnicas habituales en la época.

ser hecha "en el tiempo que se sabe es el mejor para que no se corrompa" (pero el "Pliego" del que recogemos esta frase no especifica cuál debe ser ese "tiempo"). Como maderas más recomendables se sugieren el enebro y también "el Roble Aya, verdes, recien cortados del monte". Algunas veces la colocación de puntas de hierro se propone sólo como opcional "si hubiere necesidad", sin embargo en otras, el pliego es más estricto y exige que "cada uno [pilote] tenga a lo menos de grueso un pie de Diametro con punta de fierro y aro en la cabeza". Igualmente el empleo de maquinaria de hinca se sugiere, a veces, "si no se pudiera clavar con mazos a brazo" pero en otras ocasiones se impone y reglamenta con toda precisión. "Dándoles [a los pilotes] a plomo - dice el "Pliego de Condiciones", para la construcción del nuevo puente de piedra sobre el Rio Lena" (13) - con una maza que pese a lo menos treintta arrobas disparada de la máquina que levante treinta y cinco pies, conttinuando esta operación hasta que la maza rehusse el golpe y evidencia la experiencia que no puede entrar mas, en cuyo esta do y que estan piloteados todos los cuadros de cada plantta, se han de cortar las cabezas que sobraren de los pilotes, poniéndolas enrasadas con la superficie alta del enrrejado".

Pólvora. Se trataba de un producto "estancado" y por ello de consumo restringido y cuya distribución corría a cargo del Estado, por ello todos los "Pliegos" que mencionan este artículo coinciden en la misma fórmula: "La pólvora se les suministrará a los Asentistas a coste y costas (se refiere al precio oficial más el derivado del transporte a pie de obra) de los almacenes de la Comisión con la formalidad prescrita por la Real Instrucción para evitar la mala versacion".
Como documento complementario de los pliegos de condiciones y formando parte inseparable de ellos, se redactaba una relación de las unidades de obra, que una vez establecido el contrato entre Administración y asentista serviria como referencia en las mediciones previas a cada certificación. En ocasiones la legislación exigía que esta relación viniera acompañada de una lista de precios unitarios elaborada por el facultativo autor del "Pliego" y que sirviera como referencia a los asentistas interesados en participar en la subasta. Sin embargo en algún otro momento la ley exigía que esta "relación" estuviera exenta de precios, entendiéndose, probablemente, que ello tendería a que se presentaran ofertas más ventajosas para la Real Hacienda.

\section{EL REMATE}

El siguiente paso en el procedimiento para la adjudicación de una obra por asiento era la realización del "remate", es decir de la subasta pública. Para ello, un ejemplar del "Pliego" incluyendo lugar, día y hora en que se procederia a la adjudicación de las obras, era colocado en los pueblos de la comarca unos días antes de la fecha señalada. El acto era presidido por el Intendente de provincia, o algún representante suyo, a quien acompañaba un Comisario de Guerra y el Ingeniero que la Administración había designado como "Director" de la obra, así como un escribano que levantaba acta, y tal vez algún otro representante más de la Administración pues a este respecto la normativa legal sufrió ligeros cambios a lo largo del siglo XVIII.

Los participantes presentaban por escrito sus corres- 


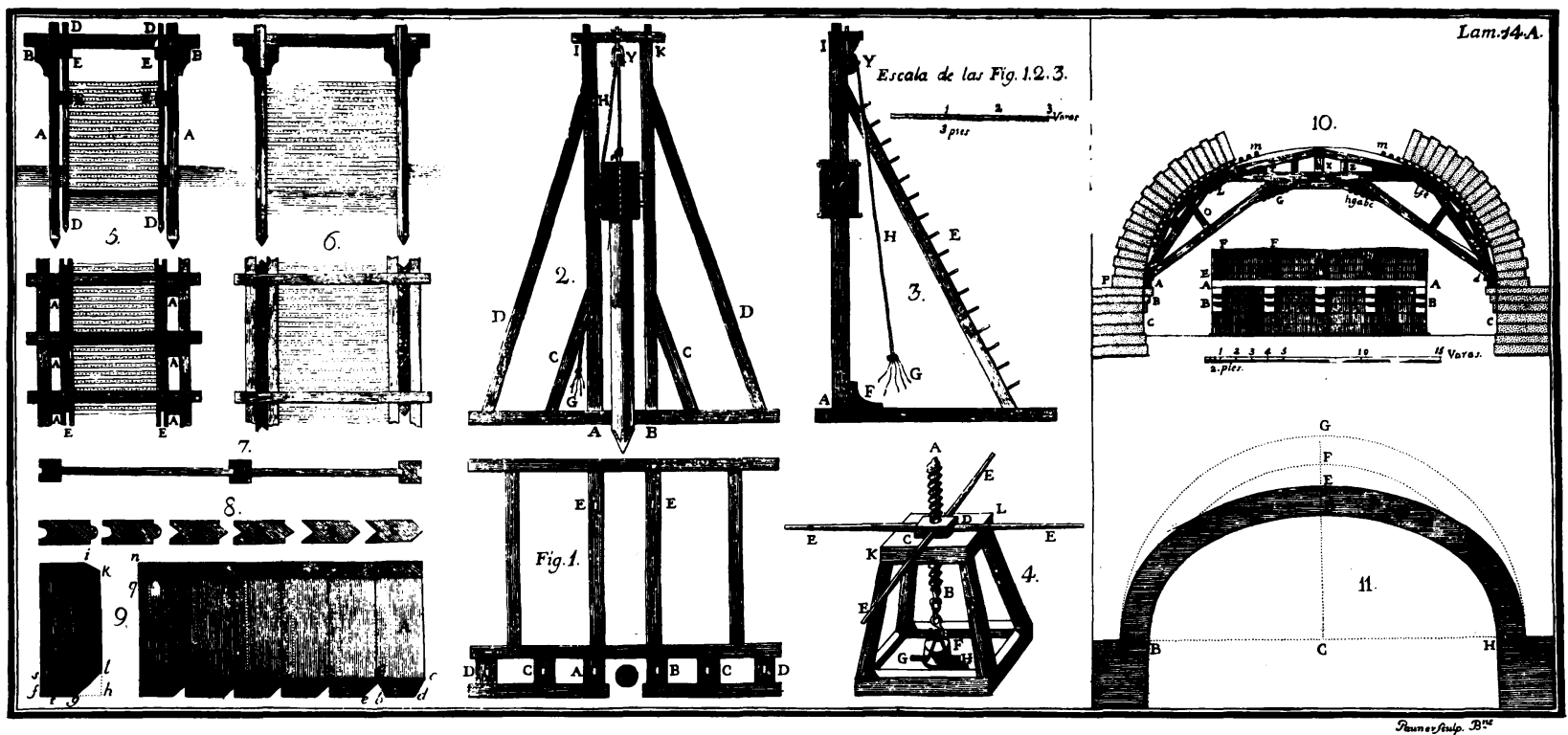

Maquinaria de hinca, según la obra de J. Muller.

pondientes "posturas", fijando los precios de las unidades de obra y matizando en lo que consideraban necesario el "Pliego de Condiciones", normalmente en el sentido de solicitar ciertos privilegios concretos que les facilitaran su trabajo una vez firmado el contrato y que con ligeras variaciones se reducian a estas cuatro solicitudes:

1.-Que se les diera libertad para que pudiera pastar el ganado empleando en la obra de forma gratuita en los terrenos comunales y valdíos del municipio en que se estuviera trabajando, y de no existir éstos, "en dehesas cerradas" obligándose el asentista, en tal caso, a abonar el precio "de suelta regular... que es por cada cabeza de ganado mayor un cuarto (14) de día y dos de noche".

2.-Que se les permitiera abrir canteras y minas para proveerse de los materiales necesarios "tanto en valdíos, comunes propios de Villa en donde mas conviniere,... como hasta en Heredades", obligándose el asentista, en este segundo caso, a satisfacer al propietario por los daños que causase.

3.--"Que si fuese necesario hacer embargo de Galeras, Caballerias menores, Carretas de Operarios se me ha de dar por parte de la RI. Hacienda - dice uno de los contratistas - todo el auxilio necesario haciendo que no lleven mas precio que el que sea regular segun la costumbre del país".

4.-Por último, y si en los itinerarios a realizar para el transporte de materiales se hacia necesario cruzar algún puente o puerto, solicitaban los asentistas que se les concediera exención en el abono de los correspon- dientes derechos, solicitud a la que usualmente se apelaba atendiendo al hecho de que las obras a realizar lo eran "en favor de la Real Hacienda".

De entre todas las "posturas" presentadas, elegía la comisión de funcionarios la del asentista cuyas condiciones entendía más beneficiosas para los intereses de la Administración (sin excepción, la de precio más bajo), y tras ello, lejos de dar por terminado el procedimiento, en cierto modo comenzaba éste, pues era entonces cuando el pregonero leía en la plaza pública las condiciones y pliego de dicho asentista, y el resto de los presentes (incluso él, obviamente) procedían, si asi lo consideraban oportuno, a proponer, ahora verbalmen. te, lo que se denominaba las "mejoras" y que podian consistir en la baja de algunas unidades de obra, o en forma de porcentaje, del total de ellas (aunque esto estuvo prohibido por la legislación en algún momento) o en la renuncia a alguna de las "ventajas" que el pliego concediera a quien "tomase el asiento", admitiéndose eventualmente como "mejora" el aceptar el contratista una fianza de mayor valor que la propuesta en el "Pliego", cuestión ésta a la que nos referiremos más adelante.

Cada mejora, tras ser aceptada, era registrada en el acta que el escribano levantaba de la operación del "remate" y a continuación se pregonaba para conocimiento público. El procedimiento venía acompañado de un ritual que evitaba que el "remate" se alargara indefinidamente; nos referimos al sistema de "la candela" que probablemente tenía en el XVIII, tradición inmemorial $y$ del que hemos encontrado referencias a lo largo de todo el siglo. El sistema, sustitutivo de la fijación de una hora precisa para la conclusión de la subasta (15), 
consistía en encender una vela (o varias, de forma consecutiva, según la costumbre de cada comarca) de tal manera que mientras "ardiera la candela" era lícito hacer una nueva "mejora" pero al apagarse ésta (o la "postrera" en los otros casos) el "remate" se daba por concluído y la obra se adjudicaba al asentista que hubiera realizado la última "mejora", todo lo cual quedaba referido en el acta a cuyo pie firmaban los funcionarios que habían presidido la subasta, el asentista en quien la obra se remataba y el escribano que daba fe (16).

\section{BAJAS TEMERARIAS}

Las "mejoras" resultantes de la aplicación de este sistema de puja no era estraño que, de medio punto en medio punto, condujeran a bajas de orden del $20 \%$ y a veces mayores, por lo que son varias las referencias que en la documentación hemos encontrado relativas a la ruina de algún asentista. Sin embargo, la cuestión de las bajas temerarias no fue tratada con suficiente detalle en la legislación del siglo XVIII, y si bien se mencionaba en el articulado de la Instrucción de Ingenieros que estuvo vigente en los caminos radiales, hacia 1776 , como veremos a continuación, las prerrogativas que en tal instrucción se concedian al Ingeniero para vetar ciertos proyectos tenían poco peso en la práctica.

A este respecto es significativo el caso de Bartolomé Amphoux quien en 1776 (16), ocupando el cargo de ingeniero comandante de las obras del camino de Galicia, intentó que fueran rechazadas todas las "posturas" que incluyeran bajas superiores al $8 \%$. El asunto llegó a oídos del Comandante General de Galicia, Félix Oneille, quien le desautorizó, adjudicando la obra a la sociedad José Roque Bieux y Compañia que había hecho una baja del $18,5 \%$ pues, "aunque no dudo - dice Oneille - de la inteligencia y conocimiento del expresado Ingeniero, me parece no es desproporcionada dicha baja, según el estilo de las obras del País, y que a serlo no dejarían de advertirlo los postores, y no se arrojarian al precipicio de su ruina...". Informado de todo ello Múzquiz, tras pedir éste opinión a Sabatini prevaleció el dictamen de Oneille. Bieux no quebró, pero sus "cuentas" eran tan justas que ello le llevó a una permanente pugna con los ingenieros encargados de las mediciones de las obras realizadas cuyos cálculos a lo largo de los siguientes dos años no era extraño que diferieran de los del asentista en la relación de uno a casi dos, lo que provocaba continuas paralizaciones de las obras del camino, acompañadas de las correspondientes instancias al Superintendente Múzquiz, que en ningún momento supo resolver la situación (17).

\section{FIANZAS}

Al no estar los "Pliegos" acompañados de una evalua(c) Consejo Superior de Investigaciones Científicas

Licencia Creative Commons 3.0 España (by-nc) ción del coste total de las obras, la fianza no se podía fijar en forma de porcentaje, lo que llevaba a que independientemente de la envergadura del proyecto se tendiera a fijar fianzas similares, en todos los casos. Una cifra manejada a menudo es la de 30.000 reales (18), aunque no es extraño que se exijan fianzas por el doble de ese valor. En ocasiones el articulado se acoge a una supuesta instancia superior y no fija cantidad alguna "ha de dar [el asentista] -exige un "Pliego"- las fianzas correspondientes en dinero obra hecha con todas las seguridades correspondientes y a satisfacción del Intendente o Comisario de Guerra que le sustituya...". Aunque la devolución de la fianza estaba reglamentada sin embargo, en los "Pliegos" se proponían usualmente procedimientos más blandos para el caso, consistentes en general en devolver parte de ella cuando hubiera sido ejecutada una fracción suficientemente importante de la obra, así, por ejemplo, en las "Condiciones... para el Asiento del Camino General de Galicia..." (19), se propone que, "para afianzar el Asiento depositarán los Impresarios treinta mil reales de vellón, los que se les reintegrar apenas se verifique haver executado en el Camino obra cuyo importe ascienda de Quarenta a Cincuenta mil reales, los que no se les satisfará hasta haber finalizado el Asiento y aprobado la obra por los Directores", lo que de hecho suponía reducir la fianza aproximadamente a la mitad, a los pocos meses del comienzo de las obras.

\section{NOTAS}

(1) Archivo Histórico Nacional, Hacienda Ig. 229A, 4 de agosto de 1749 .

(2) Archivo General de Simancas, Secretaria y Superintendencia de Hacienda, Ig. 912.

(3) Ni lo estarian hasta que el Conde de Guzmán tomó a su cargo en 1799 la Inspección de Caminos

(4) A.G.S. S.S.Ha. Ig. 910, 3 de diciembre de 1777.

(5) Aunque es este lugar adecuado para realizar un profundo análisis de la "tortuosa" evolución de los términos a que nos estamos refiriendo a lo largo de las dos últimas centurias, apuntemos que el reglamento de 14 de abril de 1836 que organizaba la dirección General de Caminos, Canales y Puertos, y establecía el "orden que debe seguirse en la ejecución de las obras públicas" desterraba de la terminología oficial la palabra "asiento", indicando, en su artículo 178 que "Las obras se ejecutaran por contrata... o por administración..." dando a ambos términos un uso enteramente análogo al que poseen en la actualidad. Pero no se entiende con ello que desde esas fechas ha tenido el Estado una actitud homogénea en cuanto a esta cuestión; por ejemplo, apenas diez años después, la "Instrucción para promover y ejecutar las obras públicas" de 10 de octubre de 1845, establecía en su artículo 5 que "Las obras nacionales como las provinciales y munjcipales pueden realizarse por 
empresa, por contrata o por administración...". En esta ocasión el vocablo "empresa" se empleaba en un sentido muy similar a lo que hoy entendemos por concesión y no es necesario aclarar que el nuevo empleo que se le quiso dar a la palabra no prosperó en absoluto en la "jerga" administrativa.

(6) Respecto de este apartado mencionado sin duda con cierto optimismo en los "Pliegos" en la documentación consultada sólo hemos podido constatar el empleo de algunas grúas, de maquinaria de hinca de pilotes para la cimentación de puentes y, con carácter muy ocasional, y específicamente en lo que se refiere a construcción de caminos, de rodillos compresores arrastrados por bueyes. Como sabemos en su "memoria sobre los medios para facilitar el comercio interior" (1791), A. de Betancourt definiendo el prototipo de ingeniero ideal, exigia que éste se hallara instruido sobre "las muchas máquinas que se han inventado para trabajar con economía en los puentes y caminos....'. Sin duda alguna, estas máquinas tardaron varias décadas en hacerse de uso común en la construcción de nuestras carreteras.

(7) En muchas ocasiones "cimbrias".

(8) "Las reglas del arte", una expresión muy utilizada en los "Pliegos".

(9) Corresponde esta cita concretamente al "Pliego" elaborado por Sabatini del que hicimos mención al principio del capítulo. Pero no nos parece que la expresión fuera de uso común pues salvo en este pliego no la hemos encontrado en ningún otro.
(10) A.G.S. S.S.Ha. Ig. 913, 3 de junio de 1775.

(11) A.G.S. S.S.Ha. Ig. 910, 26 de enero de 1778.

(12) A.G.S. S.S.Ha. Ig. 914, 17 de julio de 1775.

(13) A.G.S. S.S.Ha. Ig. 919, 7 de agosto de 1773.

(14) Un cuarto de real.

(15) Lo que habia creado problemas difíciles de resolver pues el reloj era objeto de muy raro uso en esos días.

(16) Todo ello precedido de alguna fórmula ritual que por ejemplo en Castilla tenía un tono ciertamente infantil: "A la una, a las dos y a la tercera, que buena Pro, que muy buena Pro, y buen Provecho haga al Postor" escribía el notario.

(16) A.G.S. S.S.Ha. Ig. 914.

(17) Sin duda es éste uno de los problemas a que se refiere Floridablanca, sin mencionarlo, cuando comenta en su testamente político que Múzquiz abandonó la Superintendencia de Caminos "fastidiado por lo poco que se adelantaba en ellos" y "acosado de recursos que se multiplicaban especialmente sobre los de Cataluña y Galicia".

(18) Con esa cantidad se podía construir aproximadamente un $\mathrm{km}$ de carretera en terreno medianamente accidentado.

(19) A.G.S. S.S.Ha. Ig. 913, 3 de julio de 1775.

\title{
publicación del ICCET/CSIC
}

\author{
ACUEDUCTOS ROMANOS EN ESPAÑA \\ Carlos Fernández Casado \\ Prof. Dr. Ing. de Caminos, Canales y Puertos
}

Esta publicación se compone de una serie de artículos, publicados en la Revista "Informes de la Construcción", en los cuales se hace un análisis de los acueductos romanos que existen en España y el balance de las condiciones de conservación en que se encuentra cada uno de ellos, incluyendo referencias históricas y literarias. Se ha ilustrado con la reproducción de la valiosa documentación gráfica que posee el prestigioso autor.

Un volumen encuadernado en couché, a dos colores, de $21 \times 27$ centímetros, compuesto de 238 páginas, numerosos grabados, dibujos, fotos en blanco y negro y figuras de línea.

Precio: España, 1.500 ptas., 21 \$ USA.

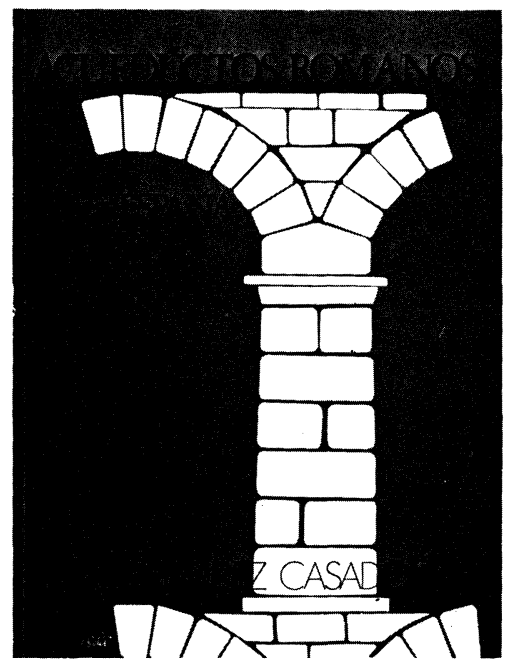

